
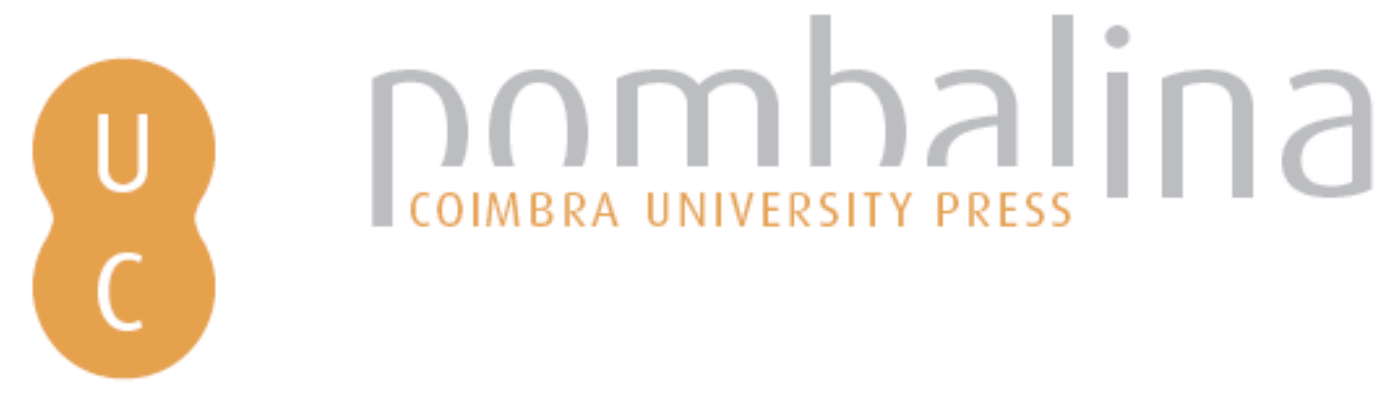

\title{
Analysis of the thermophysiological response to cooling techniques in firefighters
}

Autor(es): $\quad$ Abreu, R. Marcelo; Raimundo, António M.; Quintela, Divo A.

Publicado por: Imprensa da Universidade de Coimbra

URL

persistente:

URI:http://hdl.handle.net/10316.2/34309

DOI:

DOI:http://dx.doi.org/10.14195/978-989-26-0884-6_146

Accessed : $\quad$ 26-Apr-2023 13:12:35

A navegação consulta e descarregamento dos títulos inseridos nas Bibliotecas Digitais UC Digitalis, UC Pombalina e UC Impactum, pressupõem a aceitação plena e sem reservas dos Termos e Condições de Uso destas Bibliotecas Digitais, disponíveis em https://digitalis.uc.pt/pt-pt/termos.

Conforme exposto nos referidos Termos e Condições de Uso, o descarregamento de títulos de acesso restrito requer uma licença válida de autorização devendo o utilizador aceder ao(s) documento(s) a partir de um endereço de IP da instituição detentora da supramencionada licença.

Ao utilizador é apenas permitido o descarregamento para uso pessoal, pelo que o emprego do(s) título(s) descarregado(s) para outro fim, designadamente comercial, carece de autorização do respetivo autor ou editor da obra.

Na medida em que todas as obras da UC Digitalis se encontram protegidas pelo Código do Direito de Autor e Direitos Conexos e demais legislação aplicável, toda a cópia, parcial ou total, deste documento, nos casos em que é legalmente admitida, deverá conter ou fazer-se acompanhar por este aviso. 


\section{ADVANCES IN}

Forest Fire

\section{RESEARCH}

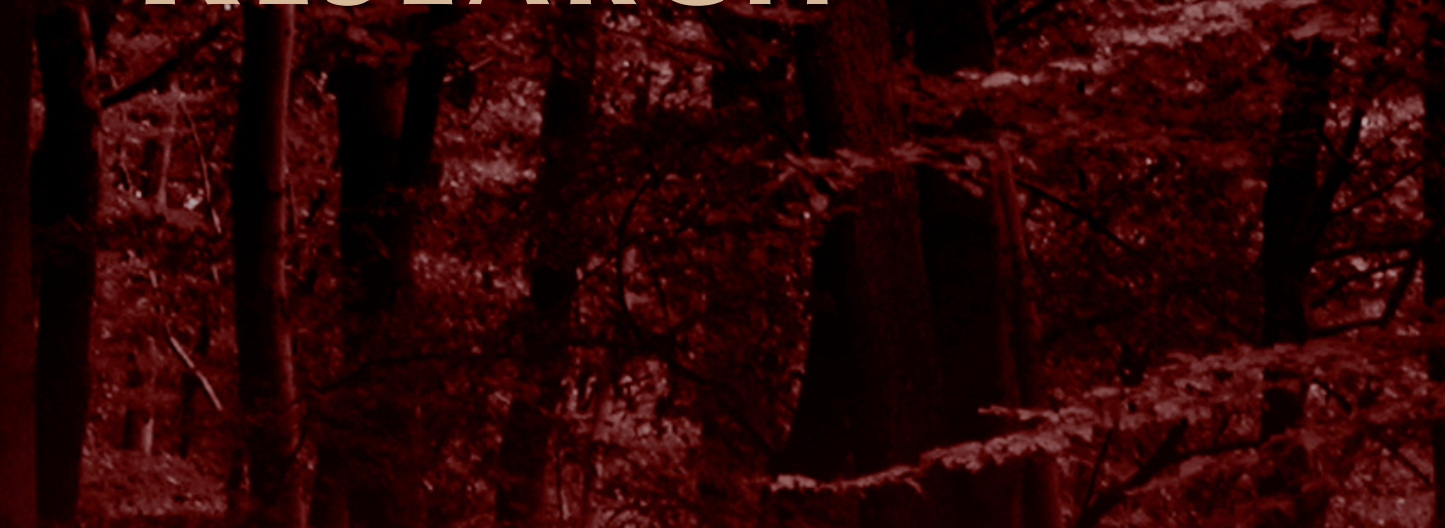

\section{DOMINGOS XAVIER VIEGAS}

\section{EDITOR}




\title{
Analysis of the thermophysiological response to cooling techniques in firefighters
}

\author{
R. Marcelo Abreu, António M. Raimundo*and Divo A. Quintela
}

ADAI-LAETA, Department of Mechanical Engineering, University of Coimbra - Pólo II, Rua Luís Reis Santos, 3030-788 Coimbra, Portugal. antonio.raimundo@dem.uc.pt; $+351.239790738$

\begin{abstract}
Firefighting has often been compared to a fight against an enemy capable of both material and lives' loss. It is a physical activity that requires a rare combination of strength, flexibility, endurance and intelligence to survive under extreme conditions. When it comes to firefighting, men fighting fires are potential victims of heat stress because they go through long periods of hard work in hot environments. The present work's target is the analysis of firefighters' thermophysiological reactions to heat stress situations caused by hyperthermia. Using a software that simulates the human body's thermophysiological behavior, several aspects, such as the fire intensity's influence on the thermal state of the firefighter, the exposure time and the body cooling technique used to attenuate heat stress, are highlighted. With the goal of embracing the most possible situations, three intensity levels of impinging radiation that come from the fire and affect men fighting fires are analyzed: low; medium; and high. Three alternative body cooling techniques are considered: the traditional one; by immersion of forearms and hands in water at $20^{\circ} \mathrm{C}$; and by immersion of forearms and hands in $10^{\circ} \mathrm{C}$ water. Normal ingestion of water during recovering breaks (matching the cooling times) was also in focus in the simulations.
\end{abstract}

Keywords: Safety firefighting; Human thermophysiological response; Body cooling techniques

\section{Introduction}

Firefighting has often been compared to a fight against an enemy capable of both material and lives' loss. It is a physical activity that requires a combination of strength, flexibility, endurance and intelligence. Men fighting fires are potential victims of heat stress because they go through long periods of hard work in very hot environments (Barr et al., 2009).

Heat stress is defined as the amount of heat that needs to be dissipated or produced in order to maintain the body in a safety thermal balance (WHO, 1969). When the thermoregulatory system is unable to compensate the overload of heat imposed to the human body, the system gets unbalanced and the individual begins to suffer from hot heat stress. This kind of thermal stress occurs due to internal factors, such as the metabolic heat and individual differences, due to the person activity intensity and the garments that uses, and due to the surrounding thermal environment (Sharkey, 1999; McLellan \& Selkirk, 2005). Any job or task that may cause an increase in the body core temperature elevates the risk of hyperthermia (heat stress caused by over accumulated heat in the body). Operations involving high air temperatures, high level of moisture, impinging radiation from heat sources, direct physical contact with hot objects, or very intense physical activities have a high potential risk of hyperthermia. Firefighters on duty are potential victims of numerous pathologies related with excess of heat and the consequent increase in body core temperature. These heat-related illnesses are introversion (violent sweating, misleading, amnesia, etc.), heat-stroke (fainting and eventually stop of sweating, central nervous system alteration, etc.), superficial skin damages (pain and first-degree burns), and permanent injuries (second-degree burns or higher, brain damage or, in more serious cases, death).

In order to satisfy all the demands of the firefighting activity, it might be necessary to use recovery strategies for physical recuperation and for body cooling as a way of thermal stress attenuation (Barr et al., 2009). The purpose of the body cooling process after the firefighting activity is to restore the 
thermophysiological balance of the body in the shortest time possible and thus avoid harmful effects to health trying at the same time help the recovery of the individual for any subsequent activity.

Body cooling techniques can be passive or active. Passive cooling methodologies are much simpler to implement then the active ones. Normally, passive cooling is implemented by the moving of the firefighter to a secluded area far from the fire front, if possible shaded, and removing some of his personal protective ensemble. Active body cooling techniques requires the same actions as the passive ones and an additional cooling process, for instance forced air convection, immersion of body segments in water, etc. The drinking of water (preferably moderately cold) is also fundamental, but for body hydration as its effect on body cooling is only marginal.

The body cooling by forced air convection is based on the use of fans in order to impose a strong air speed (Carter et al., 1999). This technique is reasonable effective but somehow unpractical to improve. By other hand, the techniques based on immersion of body parts in cold water have good efficacy if applied to areas with a high concentration of arteriovenous anastomoses, as the case of hands, forearms and legs (Magalhães et al., 2001; Barr et al., 2009). This technique is simple and easy to implement due to the availability of water supply from wells or rivers, which is usually at temperatures of the order of 15 to $20^{\circ} \mathrm{C}$, making this technique often used. Studies have shown that for an individual who is in a state of hyperthermia the water temperature should be not lower than $10^{\circ} \mathrm{C}$ in order not compromising vasodilation (Selkirk et al. 2004; Carter et al., 2007; Barr et al., 2009). In the case of immersing the forearms and the hands in water, the highest cooling rates occur when the water temperature is $10^{\circ} \mathrm{C}$ (Giesbrecht et al., 2007; Barr et al, 2009).

The main objective of this work is the establishment of secure protocols to fight high intensity fires. The emphasis will be given to the identification and analysis of the effectiveness of body cooling techniques capable to mitigate the risk of heat stress by hyperthermia. It also aims to determine the influence of the intensity of the fire on the risk of incidents related with hot heat stress, as well as the maximum exposure times of firefighting to prevent any body thermal conditions that may constitute a hazard.

Three intensity levels of radiation are considered: low, medium and high. As alternative body cooling techniques, applied during regular time-breaks, attention was given to the most traditional passive method (the firefighter goes away from the fire front to rest in a shaded location) and to the immersion of forearms and hands in water at $20^{\circ} \mathrm{C}$ and at $10^{\circ} \mathrm{C}$. During these periods the firefighter is dressed with his personal protective ensemble, but without the helmet, the balaclava, the coat, and the gloves. The normal ingestion of water was also taken into account.

\section{Calculation Tool}

To obtain the results presented in this study, a computer program implemented by the authors (Raimundo and Figueiredo, 2009; Raimundo et al. 2008 and 2012) is used for the simulation of heat and mass transfer and thermophysiological response of a male firefighter exposed to extreme environmental conditions, such as those occurring in the proximity of a high intensity fire front. This program is composed by nine modules. However, for present purposes are used only the ones for the calculation of $(i)$ person thermophysiological response, (ii) heat and water transport through the clothing, (iii) heat (by conduction, convection and radiation) and mass exchange between the external surface of clothing (or skin) and the environment and surroundings, (iv) start and evolution of skin injuries (pain and burn) and (v) detection of specific incidents within the human being.

The simulation of man thermophysiological response is based on the Stolwijk (1971) thermoregulation model, improved with knowledge found in the literature (e.g., Henriques, 1947; Weaver and Stoll, 1969; Konz et al., 1977; Wissler, 1985; Huizenga et al., 1999; Fiala et al., 1999; Tanabe et al., 2002). This enhanced 89-node model considers the human body divided in 22 segments (face, scalp, neck, chest, abdomen, upper back, lower back, pelvis, left shoulder, right shoulder, left arm, right arm, left forearm, right forearm, left hand, right hand, left thigh, right thigh, left leg, right leg, left foot and right 
foot). Each body segment is composed of 4 layers (core, muscle, fat and skin), the 89th node being the central blood compartment. The model was implemented for an average man of $1.72 \mathrm{~m}$ tall, weighing $74.43 \mathrm{~kg}$ and with $14 \%$ of body fat $\left(1.869 \mathrm{~m}^{2}\right.$ of skin). For other anthropometric data, the appropriated coefficients are proportionally changed in function of the body weight, skin area and body fat. Nevertheless, the model does not take into account the influence of barometric pressure and hydration status of the subject, because there is a lack of information in the literature about the relationship between these physical and physiological parameters and the human thermophysiological response.

The simulation of heat and water transport through the clothing is based on the formulation purposed by Havenith et al. (2002). The calculations are made for each specific human body segment. Then, individual values of the local clothing parameters (intrinsic insolation, mass, specific heat, vapour permeability and radiation emissivity) must be specified for each of the 22 human body segments considered. Each section is either completely clothed or nude.

The modeling of skin burn process implemented in the software is based on Henriques' theory (Henriques, 1947; Weaver and Stoll, 1969), which represents the skin thermal damage as chemical rate phenomena. As they don't start at same instant, the prediction of the skin pain threshold is also useful. This is important because, as reported by Stoll and Greene (1959), when the pain is felt, it is often too late to avoid a $2^{\text {nd }}$ degree skin burn or, in some extreme situations, a heat stroke or even death. Empirical correlations have been developed that allow the prediction of the time until pain is felt, some of them reported in Wenger (1988), SFPE guide (2000) and Gagnon (2000). In the present program, the onset of skin pain is marked when epidermis-dermis interface temperature ( $\left.T_{\text {edi }}\right)$ reaches $45^{\circ} \mathrm{C}$ (Havenith and Heus, 2000) or when Henriques (1947) integral injury parameter $(\Omega)$ equals 0.53 , depending on what occurs first (generally, $T_{\text {edi }}=45^{\circ} \mathrm{C}$ ).

In order to understand the significance of the calculated body temperatures, it is necessary to identify the values for which there is the probability of occurrence of specific incidents in the human body. Normally, the rectal temperature is used to identify the risk of thermal injuries. Nevertheless, the temperature of blood reaching the hypothalamus is regarded as a major afferent stimulus for the intensity of the effective response of sweating, vasomotor activity and shivering. Then, a better relationship may be expected between hypothalamus temperature $\left(T_{\text {hyp }}\right)$ and the various physiological and sensory states (Pascoe et al., 1994; Kenney et al., 2004, Raimundo and Figueiredo, 2009; Raimundo et al., 2012). In the module of the program for the detection of specific incidents, the temperature limits are set as function of the hypothalamus temperature ( $T_{\text {hyp }}$ ) following the Pascoe $e t$ al. (1994) scale: $\leq 25^{\circ} \mathrm{C} \rightarrow$ death, $\leq 28^{\circ} \mathrm{C} \rightarrow$ ventricular fibrillation, $\leq 30^{\circ} \mathrm{C} \rightarrow$ stop shivering and fainting, $\leq 34^{\circ} \mathrm{C} \rightarrow$ introversion and violent shivering, $34<T_{\text {hyp }}<39^{\circ} \mathrm{C} \rightarrow$ normal thermoregulation, $\geq 39^{\circ} \mathrm{C} \rightarrow$ introversion and violent sweating, $\geq 41^{\circ} \mathrm{C} \rightarrow$ heat stroke (stop sweating and fainting), $\geq$ $42^{\circ} \mathrm{C} \rightarrow$ brain damage (permanent injuries) and $\geq 44^{\circ} \mathrm{C} \rightarrow$ death.

\section{Problem Description}

It is assumed that the firefighter in question has a physique corresponding to the average of worldwide adult male population. This corresponds to $1.72 \mathrm{~m}$ tall, $74.43 \mathrm{~kg}$ of weight and $14.5 \%$ of body fat (Tanabe et al., 2002; Raimundo and Figueiredo, 2009).

The protocol adopted in this study submits the firefighter to several phases. Each firefighting period is followed by a time break where a body cooling technique is applied and a normal ingestion of water is also taken into account.

Three alternative body cooling techniques were analyzed: the most traditional method (the firefighter goes away from the fire front to rest in a shaded location) and the immersion of forearms and hands in water at $20^{\circ} \mathrm{C}$ and at $10^{\circ} \mathrm{C}$. With the aim to determine how long it took until the manifested of the various heat stress related pathologies, simulations were also performed without the application of any cooling technique. 
In order to verify the usefulness of each body cooling technique, simulations were made taking into account three levels of fire intensity: low, medium and high. The corresponding impinging radiation fluxes are quantified in the Table 1.

Table 1. Characterization of the impinging radiation fluxes for the various fire intensities.

\begin{tabular}{lrrr}
\hline Radiation & \multicolumn{3}{c}{ Impinging radiation fluxes $\left[\mathbf{W} / \mathbf{m}^{2}\right]$} \\
\cline { 2 - 4 } from / Intensity & \multicolumn{1}{c}{ Low } & Medium & \multicolumn{1}{c}{ High } \\
\hline North & 3000 & 6000 & 9000 \\
South & 60 & 120 & 180 \\
East & 1200 & 2400 & 3600 \\
West & 1200 & 2400 & 3600 \\
Top & 120 & 240 & 360 \\
Ground & 60 & 120 & 180 \\
\hline
\end{tabular}

The following phase sequence was assumed: neutral (stabilization), pre-firefighting, firefighting, time break with cooling, firefighting, time break with cooling, firefighting, time break with cooling.

The neutral phase is foreseen to ensure that all firefighters submitted to this protocol start equally in a state of thermal neutrality. It should be noted that at this stage it is considered that the firefighter is nude.

During pre-firefighting the firefighter is moving towards the scene of the fire or making preparations for firefighting in this vicinity. At this stage the firefighter is dressed with a shirt, pants of protective clothing and boots.

The firefighting phase is when the firefighter is in front of the fire to fight it. It is assumed that the firefighter is facing the fire and thus exposed to incident radiation from the flame which varies according to the intensity of the fire (see Table 1). At this stage the firefighter is equipped with all parts of his personal protective ensemble.

The cooling phase aims to lower the core temperature of the firefighter in order to prevent the harm caused by heat exposure and to recover him in the shortest time possible. The firefighter is dressed with protective clothing but without: the helmet, the balaclava, the coat, and the gloves.

The simulation process requires a complete characterization of each phase. Namely, it must be defined the firefighter parameters (activity intensity, posture, orientation relatively to the fire, garment and food or water intake), the description of the thermal environment (temperatures, impinging radiation, relative humidity, etc.) and several calculation controlling parameters. A short of the required parameters is summarized in Table 2.

Table 2. Summary of the parameters required for the simulation of each phase.

\begin{tabular}{|c|c|c|c|c|c|c|}
\hline \multirow[b]{2}{*}{ Parameter } & \multirow[b]{2}{*}{$\begin{array}{l}\text { Neutral } \\
\text { phase }\end{array}$} & \multirow{2}{*}{$\begin{array}{c}\text { Pre- } \\
\text { firefighting } \\
\text { phase }\end{array}$} & \multicolumn{3}{|c|}{ Fire fighting phase } & \multirow{2}{*}{$\begin{array}{c}\text { Time break } \\
\text { and cooling } \\
\text { phase }\end{array}$} \\
\hline & & & $\begin{array}{c}\text { Low } \\
\text { intensity }\end{array}$ & $\begin{array}{l}\text { Medium } \\
\text { intensity }\end{array}$ & $\begin{array}{c}\text { High } \\
\text { intensity }\end{array}$ & \\
\hline Duration & $120 \mathrm{~min}$ & $30 \mathrm{~min}$ & $20 \mathrm{~min}$ & $15 \mathrm{~min}$ & $10 \mathrm{~min}$ & $15 \mathrm{~min}$ \\
\hline Activity level & $0.8 \mathrm{met}$ & $1.5 \mathrm{met}$ & $3.0 \mathrm{met}$ & $3.0 \mathrm{met}$ & $3.0 \mathrm{met}$ & $1.0 \mathrm{met}$ \\
\hline Man posture & Sitting & Standing & Standing & Standing & Standing & Sitting \\
\hline Man orientation & North & North & North & North & North & North \\
\hline Mass of food ingested & 0 & $0.66 \mathrm{~kg}$ & 0 & 0 & 0 & $0.66 \mathrm{~kg}$ \\
\hline Temperature of food & 0 & $15^{\circ} \mathrm{C}$ & 0 & 0 & 0 & $15^{\circ} \mathrm{C}$ \\
\hline
\end{tabular}




\begin{tabular}{|c|c|c|c|c|c|c|}
\hline Specific heat of food & 0 & $\begin{array}{c}4186 \\
\mathrm{~J} /\left(\operatorname{kg}^{\circ} \mathrm{C}\right)\end{array}$ & 0 & 0 & 0 & $\begin{array}{c}4186 \\
\mathrm{~J} /\left(\mathrm{kg} .{ }^{\circ} \mathrm{C}\right)\end{array}$ \\
\hline $\begin{array}{l}\text { Clothing global intrinsic } \\
\text { insolation }\end{array}$ & 0.00 clo & 1.53 clo & 2.45 clo & 2.45 clo & 2.45 clo & 1.53 clo \\
\hline $\begin{array}{l}\text { Total mass of clothing } \\
\text { (including the helmet and } \\
\text { the boots) }\end{array}$ & $0.0 \mathrm{~kg}$ & $2.8 \mathrm{~kg}$ & $5.3 \mathrm{~kg}$ & $5.3 \mathrm{~kg}$ & $5.3 \mathrm{~kg}$ & $2.8 \mathrm{~kg}$ \\
\hline Clothing specific heat & $\begin{array}{c}1000 \\
\mathrm{~J} /\left(\mathrm{kg} .{ }^{\circ} \mathrm{C}\right)\end{array}$ & $\begin{array}{c}1000 \\
\mathrm{~J} /\left(\mathrm{kg} .{ }^{\circ} \mathrm{C}\right)\end{array}$ & $\begin{array}{c}1000 \\
\mathrm{~J} /\left(\mathrm{kg} \cdot{ }^{\circ} \mathrm{C}\right)\end{array}$ & $\begin{array}{c}1000 \\
\mathrm{~J} /\left(\mathrm{kg} .{ }^{\circ} \mathrm{C}\right)\end{array}$ & $\begin{array}{c}1000 \\
\mathrm{~J} /\left(\mathrm{kg} .{ }^{\circ} \mathrm{C}\right)\end{array}$ & $\begin{array}{c}1000 \\
\mathrm{~J} /\left(\mathrm{kg} .{ }^{\circ} \mathrm{C}\right)\end{array}$ \\
\hline $\begin{array}{l}\text { Clothing global vapour } \\
\text { permeability }\end{array}$ & 1.00 & 0.42 & 0.22 & 0.22 & 0.22 & 0.42 \\
\hline $\begin{array}{l}\text { Clothing global external } \\
\text { surface emissivity }\end{array}$ & 0.93 & 0.91 & 0.90 & 0.90 & 0.90 & 0.91 \\
\hline Air temperature & $29^{\circ} \mathrm{C}$ & $35^{\circ} \mathrm{C}$ & $35^{\circ} \mathrm{C}$ & $35^{\circ} \mathrm{C}$ & $35^{\circ} \mathrm{C}$ & $35^{\circ} \mathrm{C}$ \\
\hline Surrounding temperature & $29^{\circ} \mathrm{C}$ & $30^{\circ} \mathrm{C}$ & $40^{\circ} \mathrm{C}$ & $40^{\circ} \mathrm{C}$ & $40^{\circ} \mathrm{C}$ & $30^{\circ} \mathrm{C}$ \\
\hline Air relative humidity & $50 \%$ & $40 \%$ & $40 \%$ & $40 \%$ & $40 \%$ & $40 \%$ \\
\hline Air velocity & $0.1 \mathrm{~m} / \mathrm{s}$ & $3.0 \mathrm{~m} / \mathrm{s}$ & $5.0 \mathrm{~m} / \mathrm{s}$ & $5.0 \mathrm{~m} / \mathrm{s}$ & $5.0 \mathrm{~m} / \mathrm{s}$ & $3.0 \mathrm{~m} / \mathrm{s}$ \\
\hline Impinging radiation & 0 & 0 & \multicolumn{3}{|c|}{ Values from Table 1} & 0 \\
\hline
\end{tabular}

\section{Results and Discussion}

As far as safety is concerned, the most important indicators seem to be the times delays for the starting of heat stroke (fainting) and of skin pain, mainly the first one. These and other pathologies can occur, but only for continuous firefighting circumstances (without time breaks). This aspect is remarked in Table 3, where the instants for the beginning of skin pain, introversion, heat stroke, brain damage and lethal conditions, are represented as functions of the intensity of the radiation that impinges the firefighter.

Table 3. Time delay (after firefighting start) for the occurrence of undesired pathologies with the man for continuous firefighting circumstances.

\begin{tabular}{lccc}
\hline \multirow{2}{*}{$\begin{array}{l}\text { Time delay } \\
\text { [minutes] for }\end{array}$} & \multicolumn{3}{c}{ Impinging radiation intensity } \\
\cline { 2 - 4 } & Low & Medium & High \\
\hline Skin pain & 130 & 74 & 50 \\
Introversion & 23 & 15 & 12 \\
Heat stroke & 45 & 29 & 21 \\
Brain damage & 64 & 39 & 28 \\
Death & 128 & 74 & 50 \\
\hline
\end{tabular}

As stated in Table 3, undesired pathologies can occur with the man if no time breaks are applied. The threshold for introversion is a good indicator for exposure limits that must not be exceeded. However, even for low incident radiation flux, this pathology and worst can occur for a continuous firefighting. Skin pain situation is reached only after death. Then no pain is felt by the firefighter, which can be a trap. This fact was also reported in the bibliography (e.g. Stoll and Greene, 1959; Raimundo and Figueiredo, 2009). This is perhaps one of the reasons why many experienced firefighters refuse to wear protective clothing in some body parts (ears, hands, neck, etc.). Traditionally the ears were used by firefighters as in indicator of dangerously high temperatures. A good clothing insolation protects against the incoming of external heal but also can allow a firefighter to stay in dangerously hot places, and remain there for unsafe times without any warning. 
To avoid the undesired pathologies the firefighter must stay enough away from the fire to be exposed to impinging radiant fluxes lower than the specified in Table 1. If it is not possible, then the firefighting period must be of limited duration and followed by recovering periods. It is recommended the application of a body cooling technique during these time breaks, which is the main subject of this work.

In the analysis of the results for firefighting following the protocol defined in previous section (with recovering body cooling periods), the emphasis is given to the hypothalamus, rectal and skin temperatures and to the maximum variation of the heat stored by the body over time. This is due to the fact that these variables are considered to be the most important to characterize the evolution of the thermal state of the human body. The main conclusions will be drawn about the relationship between these factors and the intensity of impinging radiation on the firefighter and of the recovery technique used.

In Figures 1, 2 and 3 are represented the results obtained with the simulations for the evolution of the thermophysiological state of the firefighter during the protocol adopted, assuming that the firefighter keeps a distance from the fire front from which results a low intensity of incident radiation and for the three cooling techniques considered.

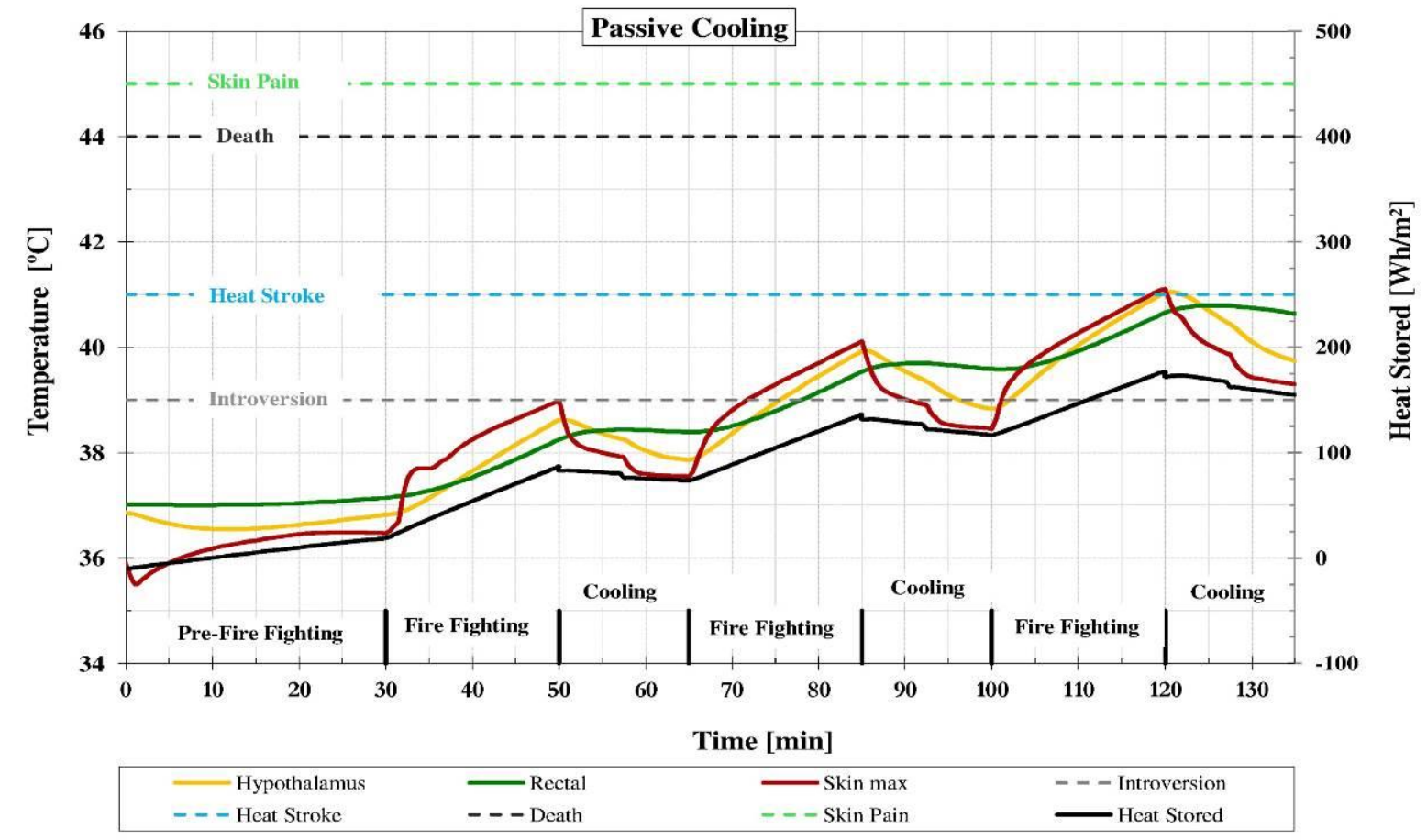

Figure 1. Evolution of firefighter thermophysiological state for low intensity incident radiation and passive cooling recovery. 


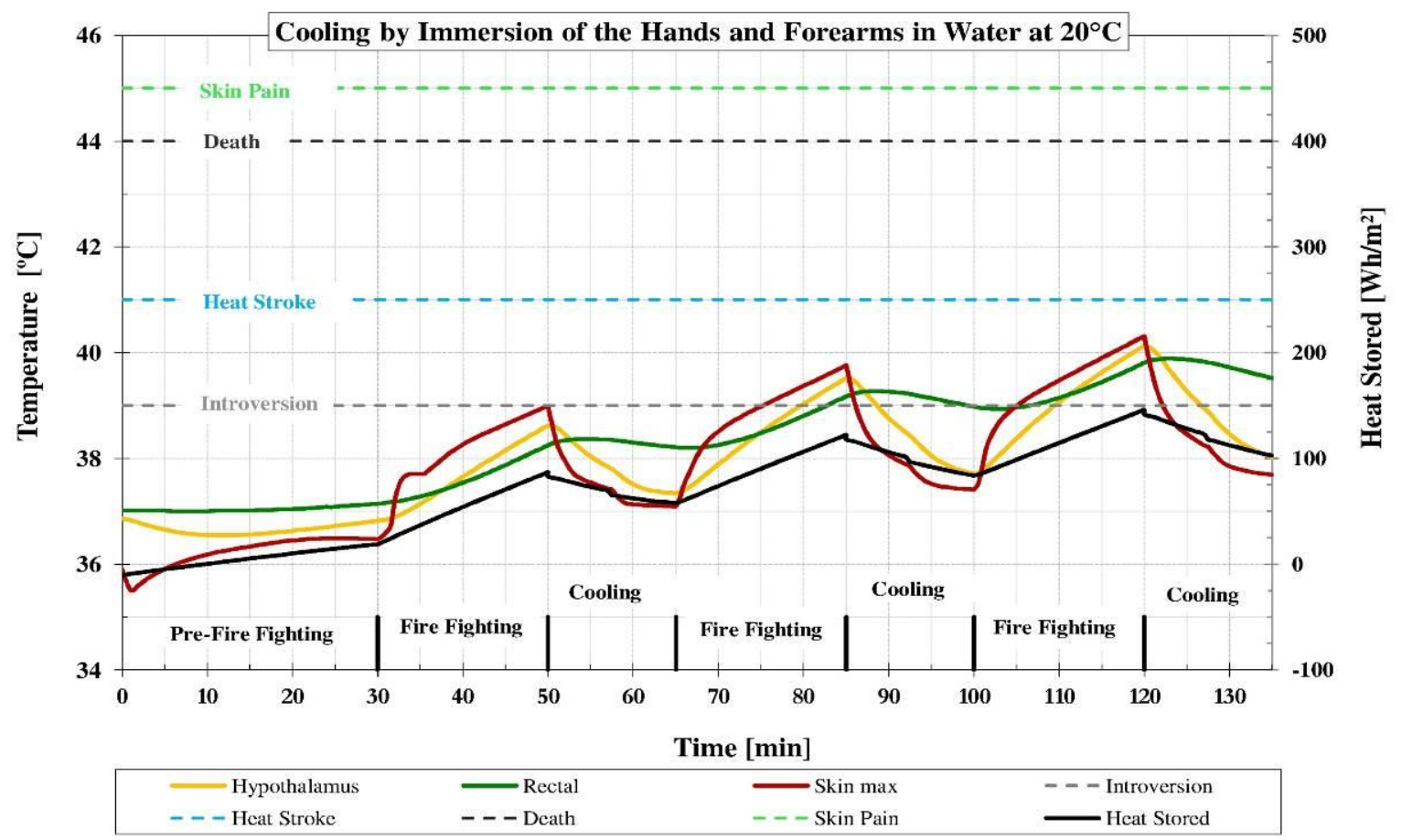

Figure 2. Evolution of firefighter thermophysiological state for low intensity incident radiation and cooling by immersion of the hands and forearms in water at $20^{\circ} \mathrm{C}$.

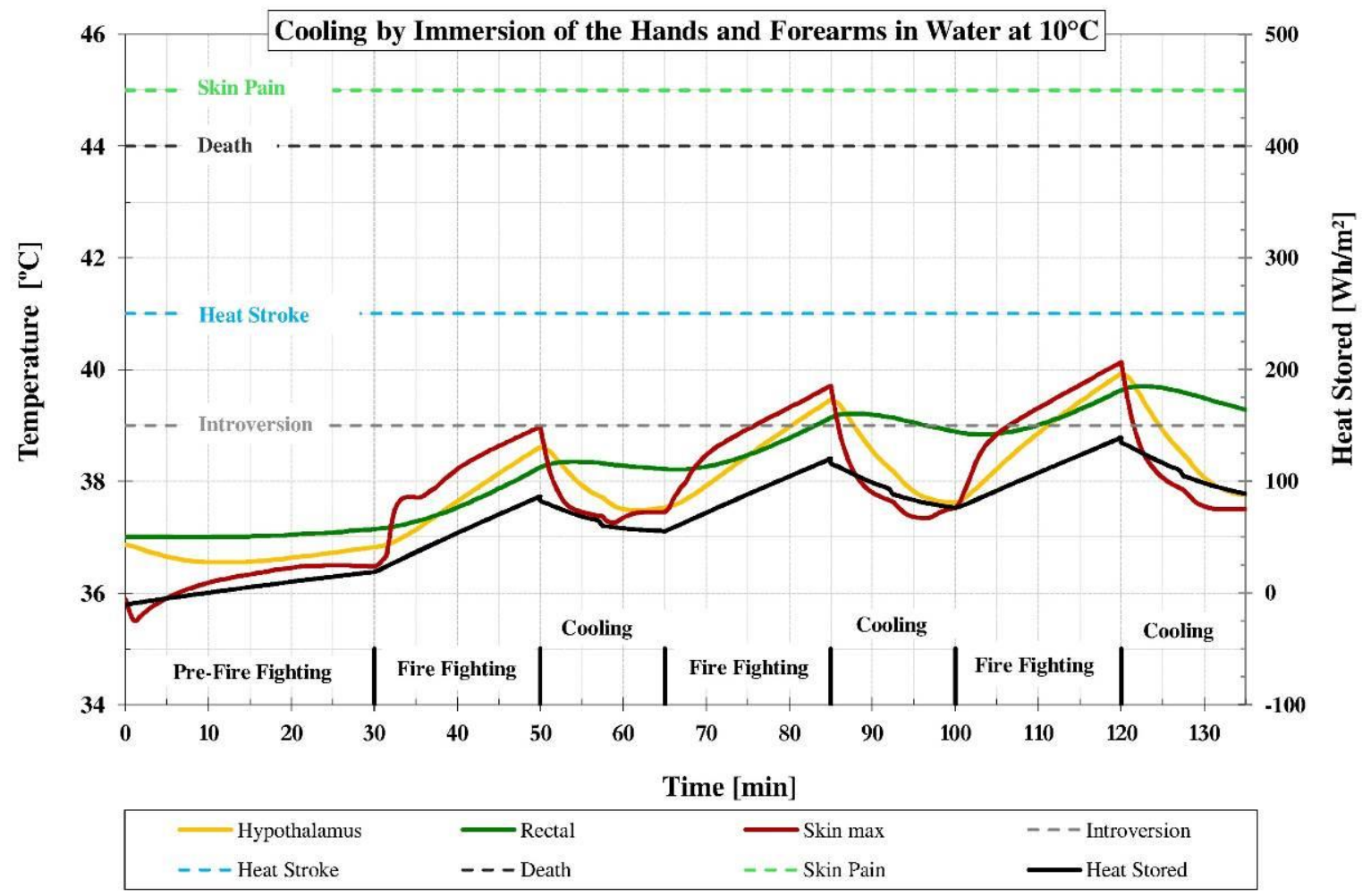

Figure 3. Evolution of firefighter thermophysiological state for low intensity incident radiation and cooling by immersion of the hands and forearms in water at $10^{\circ} \mathrm{C}$.

As it can be seen in Figures 1 to 3, passive cooling for the conditions defined in this case proves to be a recovery strategy with a reduced efficacy when compared with the techniques of immersion of the 
hands and forearms in cold water. The strategy of passive cooling (Figure 1) attenuates the heat stress felt by the firefighter but is not enough to prevent the rising of the hypothalamus temperature causing a decompensation to the thermoregulatory system, thus increasing the possibility of firefighter to come into introversion and even faint.

The cooling techniques by immersion of the hands and forearms have a greater efficacy and it would be expected that the lower the water temperature the higher the cooling produced, but it didn't happened in an obvious manner. In some cases the cooling effects are higher when the water is at $20^{\circ} \mathrm{C}$ (Figure 2) than $10^{\circ} \mathrm{C}$ (Figure 3). This is due to the fact that the temperature of the hypothalamus may not be high enough (slight degree of hyperthermia), thus the immersion of hands and forearms in water at $10^{\circ} \mathrm{C}$ promotes the appearance of cold signals, then leading to the occurrence of vasoconstriction and shivering. The vasoconstriction reduces the body cooling rate and the shivering increases the internal heat production.

By other hand, the values of the rectal temperature and of the heat stored were lower and the cooling rate $\left({ }^{\circ} \mathrm{C} / \mathrm{min}\right)$ is higher by applying the cooling technique of hands and forearms immersion in water at $10^{\circ} \mathrm{C}$. So it can be stated that this is the most effective cooling technique for heat stress reduction on fighting fires where low radiation intensity impinges the firefighter.

Similarly to the previous case, Figures 4, 5 and 6 summarize the results previewed by the simulations for the evolution of the thermophysiological state of the firefighter during the protocol adopted, but now assuming he keeps a distance from the fire front resulting in a medium intensity of incident radiation and for the three cooling techniques considered.

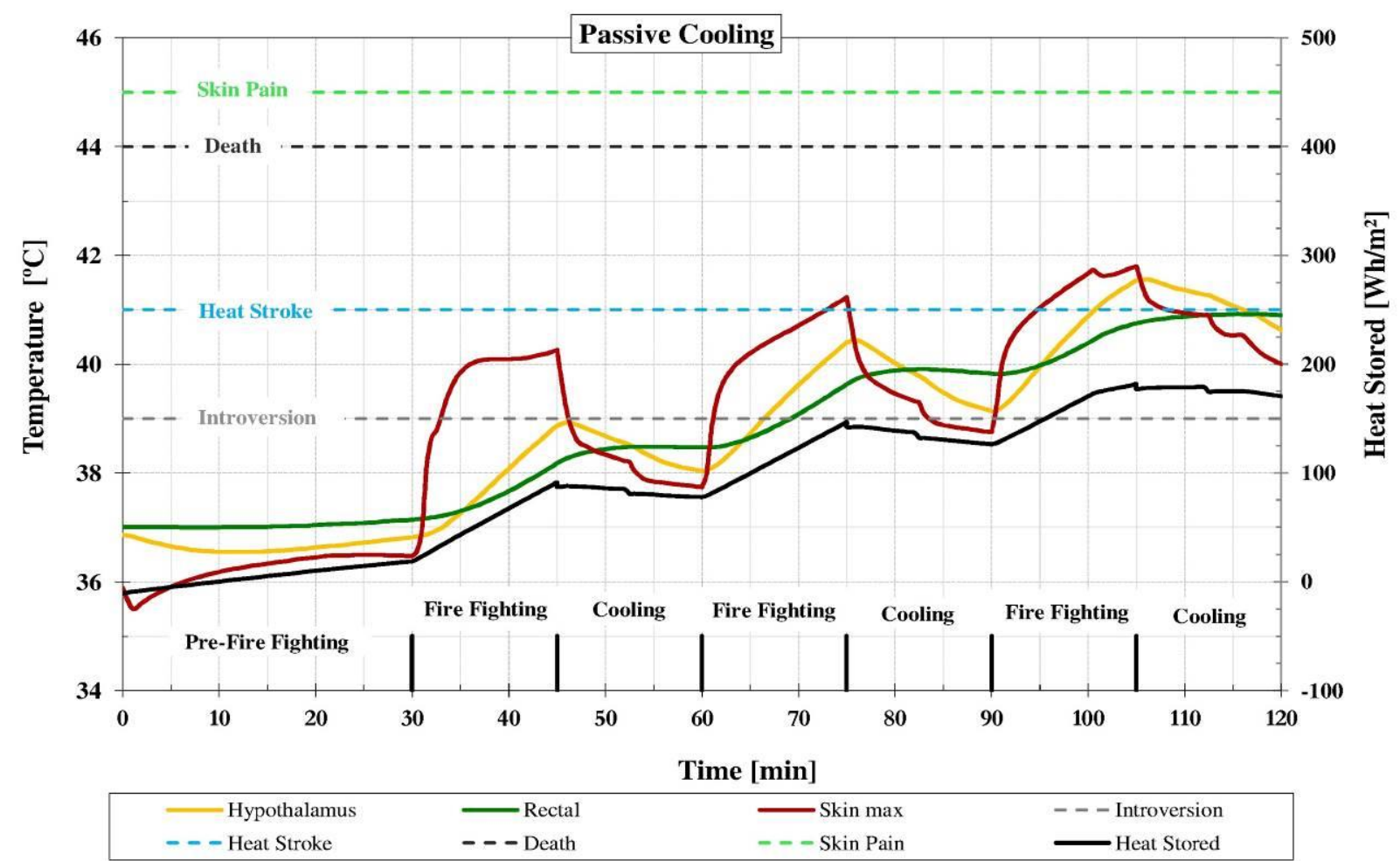

Figure 4. Evolution of firefighter thermophysiological state for medium intensity incident radiation and passive cooling recovery. 


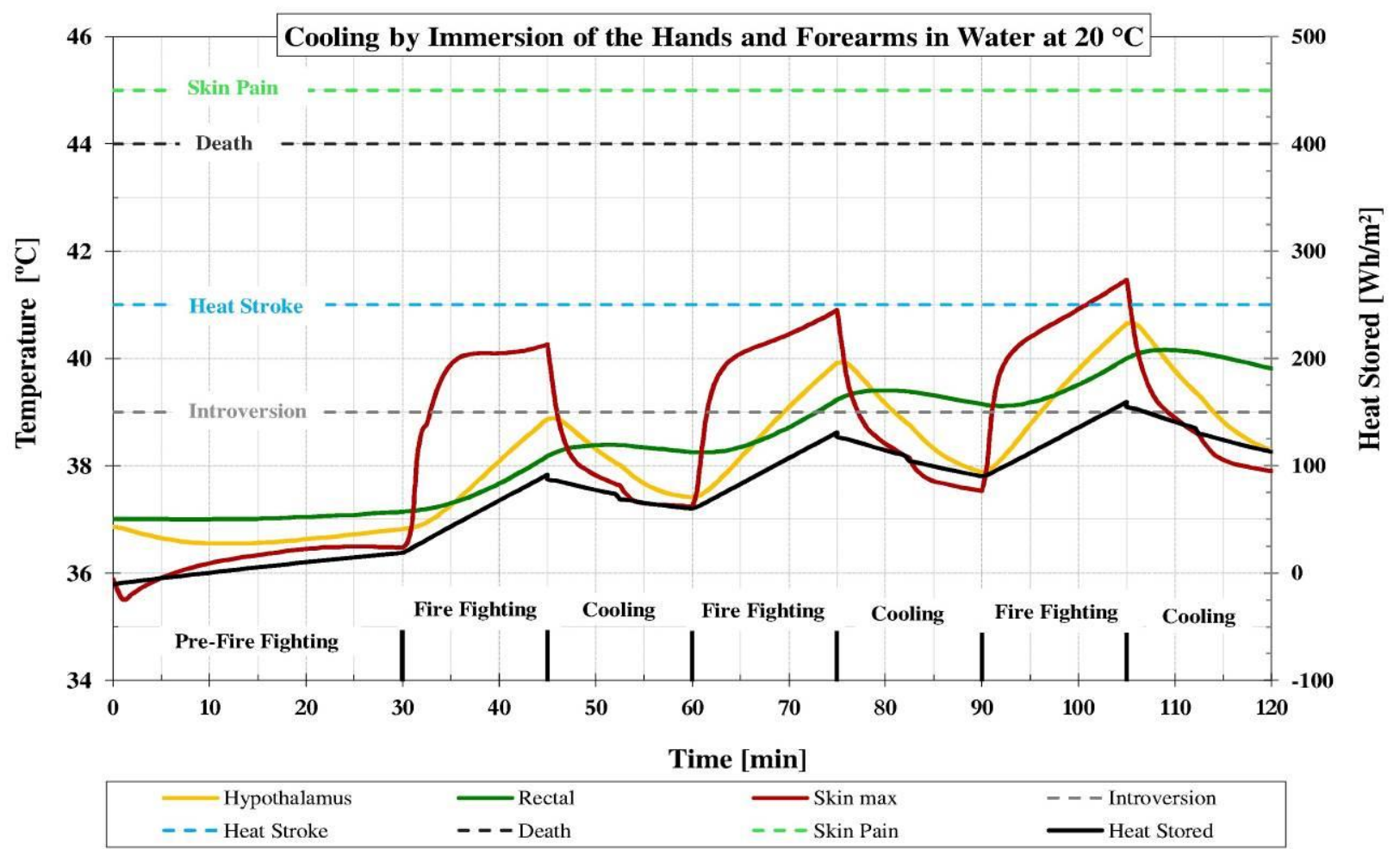

Figure 5. Evolution of firefighter thermophysiological state for medium intensity incident radiation and cooling by immersion of the hands and forearms in water at $20^{\circ} \mathrm{C}$.

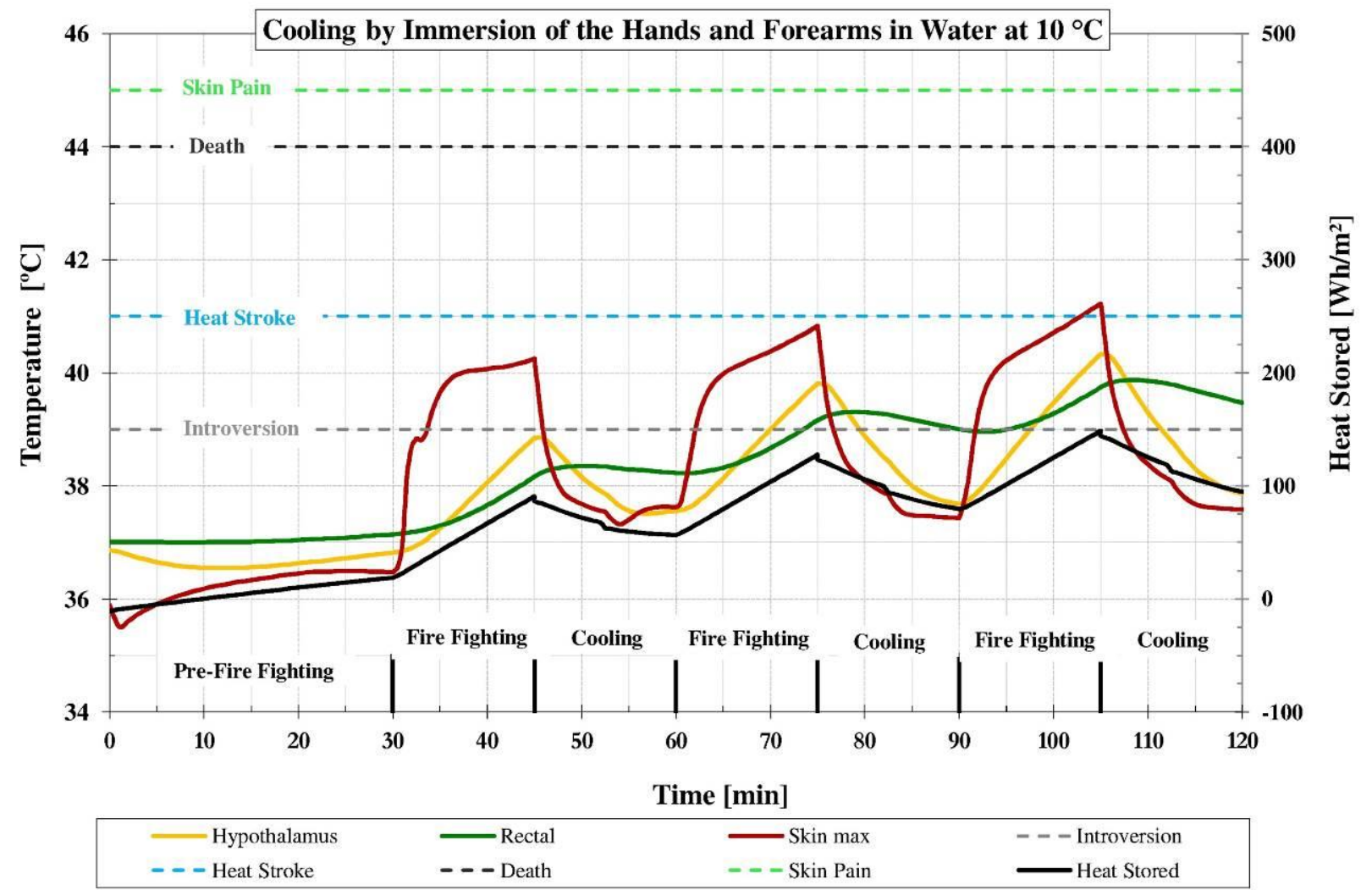

Figure 6. Evolution of firefighter thermophysiological state for medium intensity incident radiation and cooling by immersion of the hands and forearms in water at $10^{\circ} \mathrm{C}$. 
Just like what happened in the previous case, the passive cooling (Figure 4) does not show results that allow us to state that this is an efficient solution for the attenuation of heat stress. This intensity of fire causes the hypothalamus temperature to rise $2^{\circ} \mathrm{C}$ for every 15 minutes of firefighting while the passive cooling technique can only lower this temperature $1{ }^{\circ} \mathrm{C}$ for every 15 minutes of cooling. This generates a decompensation of the thermoregulatory system thus increasing the possibility of the firefighter to be affected by introversion or even by a heat stroke, which, if occurs, prevents the firefighter of getting out of the way of fire by himself.

The cooling techniques by immersion of members in cold water (Figure 5 and Figure 6) proved to be more efficient since they can provide a greater and faster reduction of hypothalamus temperature. After the entry of the firefighter in the state of introversion, they always succeeded to recover and restore the hypothalamus temperature within the range where thermoregulation occurs normally. Following the same trend previously verified the cooling technique with the immersion of hands and forearms in water at $10^{\circ} \mathrm{C}$ (Figure 5) is the more efficient, even in spite of the occurrence of vasoconstriction in a first cooling phase. This is the body cooling technique which promotes the lower values for the temperatures (hypothalamus, rectal, skin max, etc.) and for the heat stored and guaranties the higher cooling rates $\left({ }^{\circ} \mathrm{C} / \mathrm{min}\right)$. Then, also for the case of fire with a medium intensity of incident radiation this is the most effective technique in the attenuation of the heat stress.

Figures 7, 8 and 9 shown the results obtained with the simulations for the evolution of the thermophysiological state of the firefighter in the case when he is kept at a distance from the fire front leading to a high intensity of incident radiation.

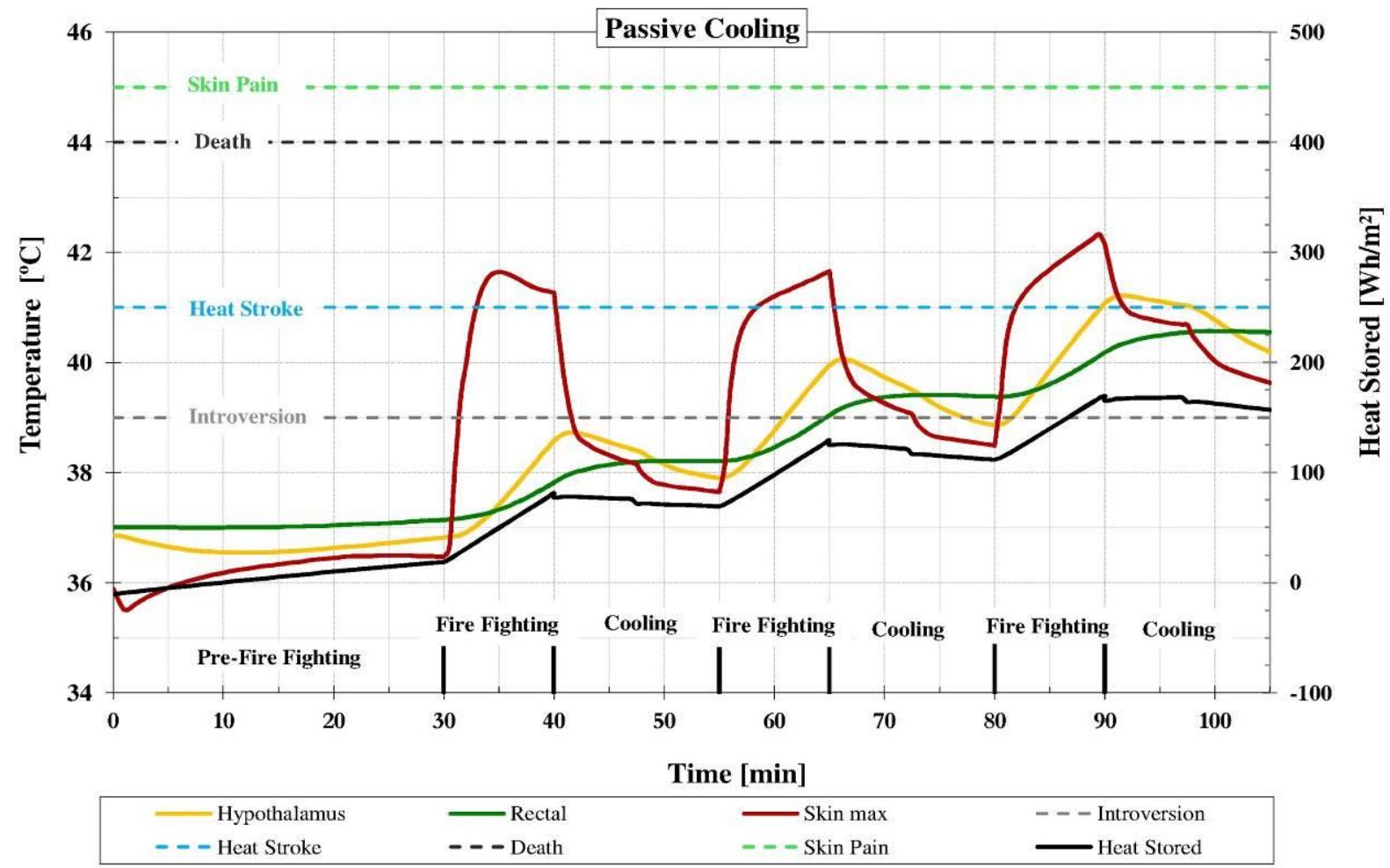

Figure 7. Evolution of firefighter thermophysiological state for high intensity incident radiation and passive cooling recovery. 


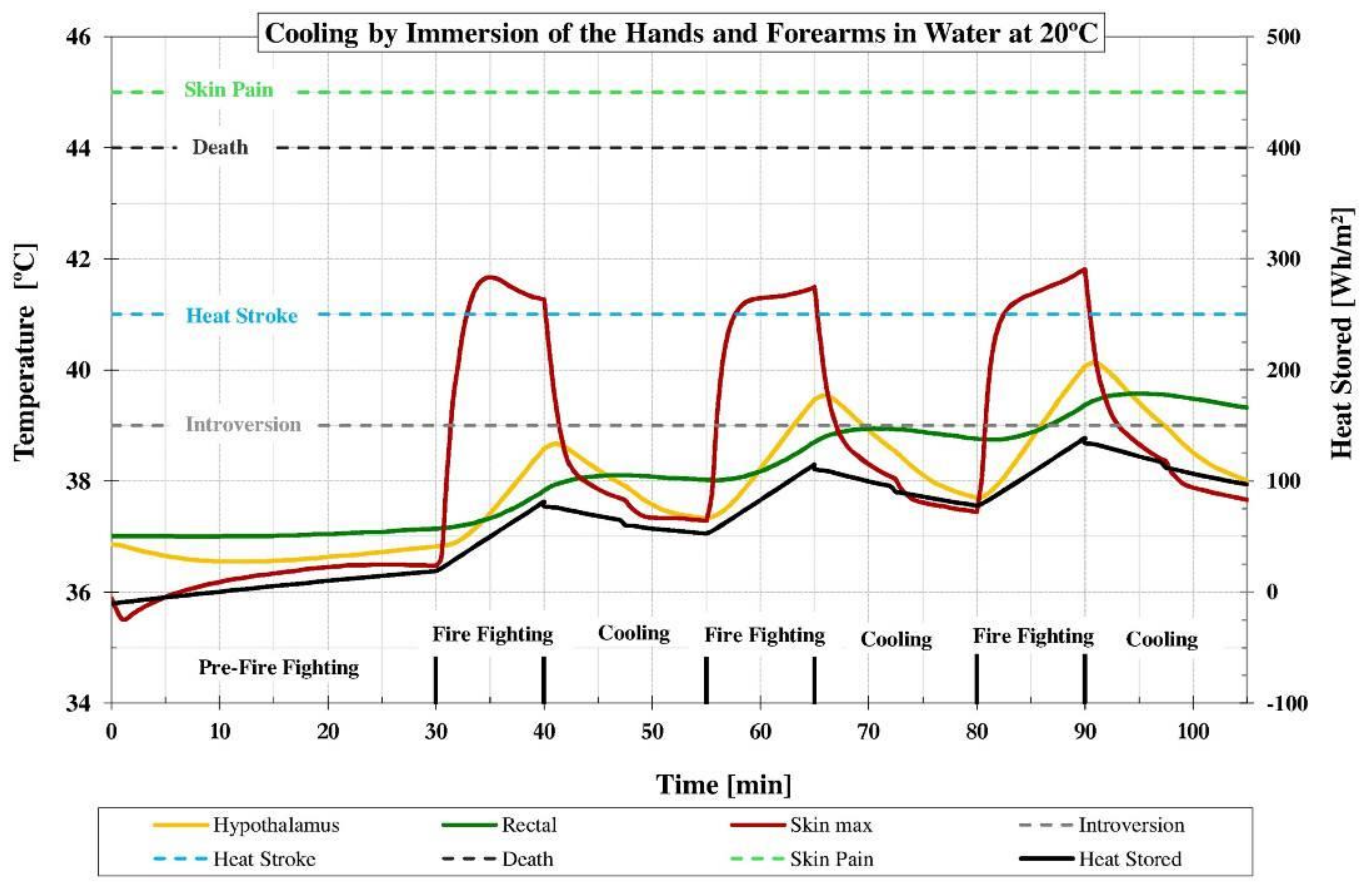

Figure 8. Evolution of firefighter thermophysiological state for high intensity incident radiation and cooling by immersion of the hands and forearms in water at $20^{\circ} \mathrm{C}$.

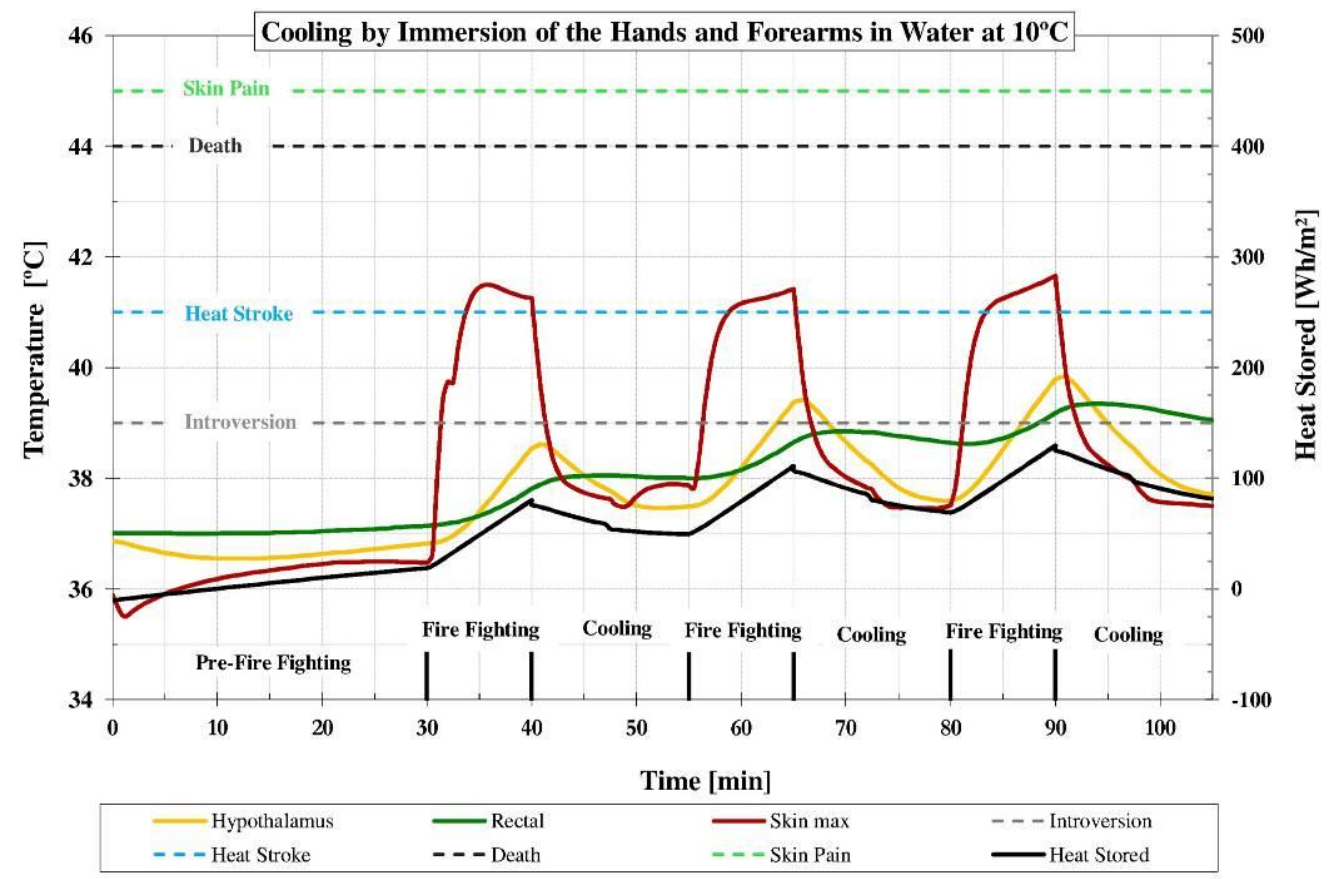

Figure 9. Evolution of firefighter thermophysiological state for high intensity incident radiation and cooling by immersion of the hands and forearms in water at $10^{\circ} \mathrm{C}$.

Following the example in the analysis of the results obtained with the two types of fires previously seen, the technique of passive cooling (Figure 7) presents a decrease of hypothalamus temperature lower than those obtained through the cooling techniques by immersion of members in cold water. Otherwise, even if vasoconstriction occurred in the first cooling phase with water at $10{ }^{\circ} \mathrm{C}$, this 
technique turned out to be the most effective one in attenuating the heat stress for the same reason mentioned above in the other two cases.

In short, among the tested, the cooling technique of immersion of the hands and of the forearms in cold water at $10^{\circ} \mathrm{C}$ proved to be the more efficient, even in spite of the occurrence of vasoconstriction (and in some cases shivering) in the first cooling phase. This is the body cooling technique which promotes the lower values for the temperatures (hypothalamus, rectal, skin max, etc.) and for the heat stored and guaranties the higher cooling rates $\left({ }^{\circ} \mathrm{C} / \mathrm{min}\right)$.

\section{Conclusions}

During this work several aspects related to the activity of fighting fires, including the intensity of the impinging radiation on the firefighters, exposure time, pathologies related with heat stress and recovery strategies (active and passive) were explored.

The intensity of the incident radiation on the firefighters during the specific fighting phase, as well as the time of heat exposure are crucial for the occurrence of heat stress.

Among the simulated cases, it can be stated that the exposure time without affecting the physical integrity of the firefighter (hypothalamus temperature lower than $39^{\circ} \mathrm{C}$ ), decreases with the increasing of the intensity of the incident radiation in the fighting phase.

In relation to the cooling techniques, it was found that the body cooling by immersion of the hands and of the forearms in cold water is much more efficient than the passive air cooling, which is in good agreement with other results available in the literature.

In spite of causing vasoconstriction, and in some cases shivering, when the degree of hyperthermia is high, the strategy of body cooling by immersion of the hands and of the forearms in cold water at 10 ${ }^{\circ} \mathrm{C}$ provides the best results in the attenuation of heat stress. Among the three body cooling techniques tested this was the one with the highest cooling rate $\left({ }^{\circ} \mathrm{C} / \mathrm{min}\right)$ and the lower values for the temperatures and for the heat stored in the human body. Then, this is the one that sustains the firefighter effectiveness during more time.

\section{References}

Barr D, Gregson W, Sutton L, Reilly T (2009), "A practical cooling strategy for reducing the physiological strain associated with firefighting activity in the heat", Ergonomics, Vol. 52 (4), pp. 413-420.

Carter JB, Banister EW, Morrison JB (1999), "Effectiveness of rest pauses and cooling in alleviation of heat stress during simulated fire-fighting activity", Ergonomics, Vol. 42 (2), pp. 299-313.

Fiala D, Lomas KJ, Stohrer M (1999), "A computer model of human thermoregulation for a wide range of environmental conditions - the passive system”, J. Applied Physiology, Vol. 87, pp. 19571972.

Gagnon BD (2000), "Evaluation of new test methods for firefighting clothing”, MSc thesis, Worcester Polytechnic Institute.

Giesbrecht GG, Jamieson C, Cahill F (2007), "Cooling hyperthermic firefighters by immersing forearms and hands in $10^{\circ} \mathrm{C}$ and $20^{\circ} \mathrm{C}$ water", Aviation Space Environmental Medicine, Vol. 78, pp. 561-567.

Havenith G, Heus R (2000), "Ergonomics of protective clothing”, Proc. of Nokobetef 6 and $1^{\text {st }}$ European Conference on protective clothing. Kuklane, K. and Holmér, I., (eds.), Stockholm, Sweden, May 7-10.

Havenith G, Holmér I, Parsons K (2002), "Personal factors in thermal comfort assessment - clothing properties and metabolic heat production", Energy and Buildings, Vol. 34, pp. 581-591. 
Henriques F (1947), "Studies of thermal injury V. The predictability and the significance of thermally induced rate processes leading to irreversible epidermal injury", Archives of Pathology, Vol. 43, pp. 489-502.

Huizenga C, Zhang H, Duan T, Arens E (1999), “An improved multinode model of human physiology and thermal comfort”, Proceedings of IBPSA Building Simulation 99, Kyoto, Vol. 1, pp 353-359.

Kenney W, DeGroot D, Holowatz L (2004), "Extremes of human heat tolerance - life at the precipice of thermoregulatory failure", J. Thermal Biology, Vol. 29, pp. 479-485.

Konz S, Hwang C, Dhiman B, Duncan J, Masud A (1977), "An experimental validation of mathematical simulation of human thermoregulation", Computers in Biology and Medicine, Vol. 7, pp. 71-82.

Magalhães S, Albuquerque RR, Pinto JC, Moreira AL (2001), "Termorregulação", Faculdade de Medicina da Universidade do Porto, Serviço de Fisiologia.

McLellan TM, Selkirk GA (2005), "The management of the heat stress for the firefighter", DRDC, Toronto, Canada.

Pascoe DD, Bellingar TA, McCluskey BS (1994), "Clothing and exercise. II. Influence of clothing during exercise/work in environmental extremes", Sports and Medicine, Vol. 18, pp. 94-108.

Raimundo AM, Oliveira AVM, Gaspar AR, Quintela DA (2008), "Thermophysiological response of human beings working in cold thermal environments", $7 \mathrm{i} 3 \mathrm{~m}-7^{\text {th }}$ International Thermal Manikin and Modelling Meeting, 3-5 of September, Coimbra, Portugal, pp 1-11.

Raimundo AM, Figueiredo AR (2009), "Personal protective clothing and safety of firefighters near a high intensity fire front”, Fire Safety Journal, Vol. 44, pp. 514-521.

Raimundo AM, Oliveira AVM, Quintela DA, Gaspar AR (2012), "Development and validation of a computer program for simulation of the human body thermophysiological response", $2^{\text {nd }}$ Portuguese Meeting in Bioengineering, Portuguese chapter of IEEE-EMBS, Coimbra, Portugal, 23-25 February, pp. 1-4.

Selkirk G, McLellan TM, Wong J (2004), "Active versus passive cooling during work in warm environments while wearing firefighting protective clothing", Journal of Occupational Environment and Hygiene, Vol. 1, pp. 521-531.

SFPE Task Group on Engineering Practices (2000), "Predicting $1^{\text {st }}$ and $2^{\text {nd }}$ degree skin burns from thermal radiation", Society of Fire Protection Engineers, Bethesda, MD.

Sharkey BJ (1999), "Heat stress", Wildland firefighter health and safety recommendations, April 1999 Conference, Missoula Technologic and Development Center, USDA Forest Service, Montana.

Stoll A, Greene L (1959), "Relationship between pain and tissue damage due to thermal radiation", Journal of Applied Physiology, Vol. 14, pp. 373-382.

Stolwijk JAJ (1971), “A mathematical model of physiological temperature regulation in man”, NASA contractor report CR-1855, NASA, Washington DC.

Tanabe S, Kobayashi K, Nakano J, Ozeki Y, Konishi M (2002), "Evaluation of thermal comfort using combined multi-node thermoregulation $(65 \mathrm{MN})$ and radiation models and computational fluid dynamics (CFD)", Energy and Buildings, Vol. 34, pp. 637-646.

Weaver J, Stoll A (1969), "Mathematical model of skin exposed to thermal radiation", Aerospace Medicine, Vol. 40, pp. 24-30.

Wenger CB (1988), "Human heat acclimatization", In: Pandolf K, Sawka M, Gonzalez R, eds, Human performance physiology and environmental medicine at terrestrial extremes. Indianapolis Benchmark Press (now: Cooper Publishing Group), pp. 153-197.

WHO (1969), "Health factors involved in working under conditions of heat stress", World Health Organization, Technical Report Series, no 412, Genève.

Wissler EH (1985), "Mathematical simulation of human thermal behaviour using whole body models", In: Shitzer A, Eberhart RC, eds, Heat transfer in medicine and biology - analysis and applications. Plenum, New York London, pp 325-373. 